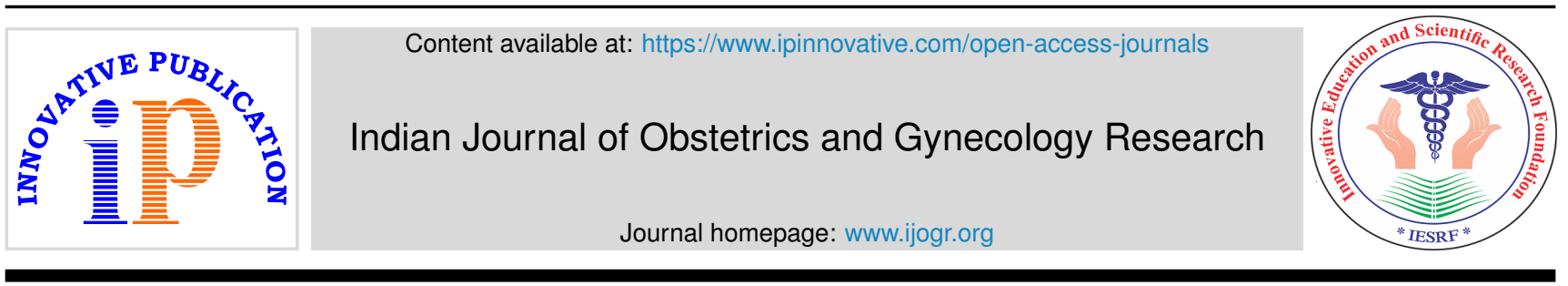

Original Research Article

\title{
A comparative study of efficacy of rectal misoprostol with intravenous methyl ergometrine and intramuscular PGF2 $\alpha$ in active management of third stage of
} labor

\author{
Suhail Iqbal ${ }^{1, *}$, Mehak Ayoob Malik ${ }^{1}$, Manju Aggarwal' ${ }^{2}$, Radheshyam Bairwa ${ }^{2}$ \\ ${ }^{1}$ Dept. of Obstetrics and Gynecology, Government Medical College, Baramulla, Jammu and Kashmir, India \\ ${ }^{2}$ Dept. of Obstetrics and Gynecology, Jhalawar Medical College \& S.H.K.B.M Hospital, Jhalawar, Rajasthan, India
}

\section{A R T I C L E I N F O}

\section{Article history:}

Received 10-06-2020

Accepted 20-06-2020

Available online 07-12-2020

Keywords:

Active management of third stage of labor

Intravenous methyl ergometrine

Intramuscular PGF2 $\alpha$

Post partum hemorrhage

Rectal misoprostol

\begin{abstract}
A B S T R A C T
Background: $\mathrm{PPH}$ is almost entirely a preventable condition when management is based on scientifically proven methods. It occurs in approximately $4 \%$ of vaginal deliveries, and estimates are that it causes significant morbidity and $25 \%$ of all the maternal child birth related deaths. We conducted this study with the following aims to compare the effectiveness of rectal misoprostol $(600 \mathrm{mcg})$ with intravenous methylergometrine $(0.2 \mathrm{mg})$ and intramuscular PGF2 $\alpha(125 \mathrm{mcg})$. To find out the percentage of pregnant women having postpartum hemorrhage, amount of blood loss and efficacy and safety of uterotonic drugs during third stage of labor.

Materials and Methods: Patients with full-term singleton pregnancy in the age group of 20-35 years admitted in the maternity ward for vaginal delivery were enrolled in the study after taking written informed consent. The third stage of labor was actively managed in these patients by either $600 \mathrm{mcg}$ of misoprostol per rectally (Group A) or $0.2 \mathrm{mg}$ of IV methylergometrine (Group B) or $125 \mathrm{mcg}$ of PGF $2 \alpha$ intramuscularly (Group C) and some were given any prophylactic oxytocic (Group D).

Results: Majority 110 (55\%) of the studies participants were in the age group of 20-24 years. Moreover, 109 (54.5\%) belonged to upper middle (II) socioeconomic class as per modified Kuppuswamy's socioeconomic scale update for 2018. Only, 7 (3.5\%) of the participants were grand multipara's while 24 (12\%) had gestational age greater than 40 weeks. Mean maternal age, gestational age and duration of third stage of labor was comparable in all the study groups. Maximum amount of blood loss was seen among participants who were in control group $(201.80 \pm 122.81 \mathrm{ml})$ and the maximum 'mean difference in Hb' was also seen in control group $(0.83 \mathrm{gm} \%)$. Reported side effects during the study included diarrhea, nausea, shivering and vomiting in (1.5\%) participants. Postpartum hemorrhage and retained placenta was reported among 7 $(3.5 \%)$ and $2(1 \%)$ participants only.

Conclusion: Misoprostol can be used as a safe and effective alternative agent in active management of third stage of labor.

(C) This is an open access article distributed under the terms of the Creative Commons Attribution License (https://creativecommons.org/licenses/by/4.0/) which permits unrestricted use, distribution, and reproduction in any medium, provided the original author and source are credited.
\end{abstract}

\section{Introduction}

Worldwide, one of the leading causes of maternal morbidity and mortality is attributed to postpartum hemorrhage (PPH). ${ }^{1} \mathrm{PPH}$ is almost entirely a preventable condition when management is based on scientifically proven methods. It occurs in approximately $4 \%$ of vaginal

\footnotetext{
* Corresponding author.

E-mail address: isuhaillove@gmail.com (S. Iqbal).
}

deliveries, and estimates are that it causes significant morbidity and $25 \%$ of all the maternal child birth related deaths. ${ }^{2}$ As recommended by World Health Organization (WHO), active management of the third stage of labor (AMTSL) is a critical intervention for the prevention of PPH. Active management of the third stage of labor is composed of mainly three components:(a) Immediately after the delivery, administration of a uterotonic, preferably 
oxytocin; (b) For the delivery of placenta safely, controlled cord traction (CCT) maneuver; and (c) soon after the delivery of placenta, uterine massage is to be done. Over the years, consensus has been reached by obstetricians that the use of uterotonic drugs is more effective in reducing the duration of the third stage of labor, decreased incidence of retained placenta, reduced amount of blood loss, and hence is an effective way to reduce morbidity and mortality associated with puerperium. ${ }^{3}$ The commonly used uterotonic agents for the prevention of PPH include oxytocin, misoprostol and methyl ergometrine. The main drawback with the use of oxytocin includes, reduced potency when stored in a suboptimal environment. ${ }^{4}$ Misoprostol is also widely used as an active uterotonic agent because of numerous advantages with regard to its route of administration. It can be administered through various routes, orally, rectally, sublingually or even vaginally. Moreover, the use of prostaglandins for the treatment of $\mathrm{PPH}$ even after failure of conventional agents is well reported in the literature. PGF $2 \alpha$ is a well established uterotonic agent used at the time of delivery which complements the physiological process during labor by causing contraction of uterine contractions and thus eventually help in reducing blood loss. 5

We conducted this study with the following aims and objectives:-

1. To compare the effectiveness of rectal misoprostol $(600 \mathrm{mcg})$ with intravenous methylergometrine $(0.2 \mathrm{mg})$ and intramuscular PGF $2 \alpha(125 \mathrm{mcg})$ in active management of $3^{r d}$ stage of labor.

2. To find out the percentage of pregnant women having postpartum hemorrhage in study population.

3. To assess the amount of blood loss during third stage of labor.

4. To assess the efficacy and safety of misoprostol $(600 \mathrm{mcg})$ per rectally, intravenous methyl ergometrine $(0.2 \mathrm{mg})$ and intramuscular PGF $2 \alpha(125 \mathrm{mcg})$ in active management of third stage of labor.

\section{Materials and Methods}

This retrospective cohort study was conducted in the Department of Obstetrics and Gynecology of Jhalawar Medical College \& S.H.K.B.M hospital, Jhalawar between January 2017-May 2018. Patients with full-term singleton pregnancy in the age group of 20-35 years admitted in the maternity ward for vaginal delivery were enrolled in the study after taking written informed consent. Patients who had hemoglobin $<8 \mathrm{~g} / \mathrm{dL}$, previous history of $\mathrm{PPH}$, pregnancy-induced hypertension, mal-presentations, coagulation abnormalities, antepartum hemorrhage, intrauterine device, history of previous cesarean section, medical disorders such as diabetes, heart disease, stroke, peripheral vascular disorders, epilepsy, asthma, liver and kidney disorders, uterine rupture, or scar dehiscence were excluded from the study. A sample size of 198 was calculated using the formula $\left[\mathrm{t}^{2} \times \mathrm{p}(1-\mathrm{p}) / \mathrm{e}^{2}\right]$ where $\mathrm{p}=$ proportion of patients admitted in labor room \& meeting inclusion \& exclusion criteria per day) $4 / 28$ and $e=$ allowable error. Sample size of 198 was rounded off to 200. A total of 668 pregnant women attended the hospital fulfilling the inclusion criteria, but only 200 pregnant women were included in the study using a convenient type of sampling. The decision of management protocol was based on the experience of the treating Obstetrician who had more than 20 years of experience in the field of Obstetrics and Gynecology. The decision of treatment was based on the initial physical, abdominal and biochemical findings. The study groups were formed retrospectively after the pregnant women were treated and discharged. Each participant was categorized in 4 groups until the required sample size of the groups was achieved. To avoid any ethical issues, no one was denied any kind of treatment depending on case to case basis.

The third stage of labor was actively managed in these patients by either $600 \mathrm{mcg}$ of misoprostol per rectally (Group A) or $0.2 \mathrm{mg}$ of IV methylergometrine (Group B) or $125 \mathrm{mcg}$ of PGF $2 \alpha$ intramuscularly (Group C) and some were given prophylactic oxytocic (Group D). Data were recorded for a total of 200 cases with 50 cases in each group. The placenta was delivered by CCT (modified Brandt-Andrews method) and uterine massage was given in all cases.

The blood loss during the third stage of labor was measured in a blood collecting bag (BRASSS-V-DRAPE). Blood clots were weighed separately considering $1 \mathrm{~g}$ equal to $1 \mathrm{~mL}$ of blood. Blood-soaked swabs were weighed, the known dry weight subtracted, and the calculated volume was added to the volume of blood in the measuring bag to get the total blood loss. Duration of the third stage of labor for each case was also noted. Maternal hemoglobin and hematocrit were repeated $24 \mathrm{~h}$ after the delivery, and the fall in hemoglobin and hematocrit was taken as an objective measure of blood loss. The occurrence of side effects such as nausea, vomiting, headache, shivering, fever, and diarrhea was noted for the next $24 \mathrm{~h}$.

\subsection{Statistical analysis}

Data was entered in a Microsoft Excel spreadsheet. Continuous variables were summarized as mean and standard deviation. Categorical variables were summarized as percentages. Chi-square test was used to test independence between two categorical variables. A p-value of less than 0.05 was considered statistically significant. All statistical analysis was done using SPSS 20.0. 


\subsection{Ethical clearance}

The study was approved by the institutional ethics committee before the commencement of the study.

\section{Results}

The socio-demographic details of the studied participants are described inTable 1. Majority $110(55 \%)$ of the studies participants were in the age group of 20-24 years. Moreover, $109(54.5 \%)$ belonged to upper middle (II) socioeconomic class as per modified Kuppuswamy's socioeconomic scale update for $2018 .^{6}$ Only, 7 (3.5\%) of the participants were grand multipara's while $24(12 \%)$ had gestational age greater than 40 weeks.

The comparison of different study groups based on the uterotonic drug used is shown inTable 2. Mean maternal age, gestational age and duration of third stage of labor was comparable in all the study groups. There was no such statistical significance found. When blood loss was compared among various groups, maximum amount of blood loss was seen among participants who were in control group ( $201.80 \pm 122.81 \mathrm{ml})$ followed by Carboprost group $(168.80 \pm 79.37 \mathrm{ml})$, followed by ergometrine group (152 $\pm 52.83 \mathrm{ml})$ and least in misoprostol group (139.20 \pm 106.92 $\mathrm{ml})$. There was a statistical significance in the mean blood loss among different groups $(\mathrm{P}=0.007)$. The maximum 'mean difference in $\mathrm{Hb}$ ' was seen in control group $(0.83 \mathrm{gm}$ $\%$ ) followed by Carboprost group (0.76 gm \%), ergometrine group (0.71 gm \%) and minimum difference was seen in misoprostol group $(0.59 \mathrm{gm} \%)$. There was a statistical significance in 'mean difference in $\mathrm{Hb}$ ' among groups $(\mathrm{P}$ $=0.022$ ).

Table 3 shows the reported side effects of drugs among different study groups. A total of $15(7.5 \%)$ participants reported with side effects, maximum 10 (5\%) in the Carboprost group. The reported side effects included diarrhea, nausea, shivering and vomiting in $(1.5 \%)$ participants. The association of the drug group and the reported side effects was statistically significant $(\mathrm{p}=0.049)$.

Complications reported during the study are enlisted in Table 4. Majority of the study participants did not report any complication. Postpartum hemorrhage and retained placenta was reported among $7(3.5 \%)$ and $2(1 \%)$ participants only.

\section{Discussion}

Postpartum hemorrhage is an excessive bleeding (more than $500 \mathrm{ml}$ in vaginal delivery or more than 1000 $\mathrm{ml}$ in caesarean section) following delivery of fetus. ${ }^{7}$ It can be atonic when bleeding is from implantation site or traumatic when bleeding is due to trauma to genital track. Postpartum hemorrhage is leading cause of maternal mortality. Although maternal mortality rates declined greatly in developed world, PPH remains a leading cause of maternal mortality in developing countries. In
Table 1: Socio-demographic details of study participants

\begin{tabular}{lcc}
\hline Variable & Frequency & Percentage \\
Age & 110 & 55 \\
20-24 Years & 64 & 32 \\
25-29 Years & 22 & 11 \\
30-34 Years & 4 & 2 \\
>34 Years & & \\
Socioeconomic status & 16 & 8 \\
Upper (I) & 109 & 54.5 \\
Upper Middle (II) & 49 & 24.5 \\
Lower Middle (III) & 17 & 8.5 \\
Upper Lower (IV) & 9 & 4.5 \\
Lower (V) & & \\
Parity & 96 & 48 \\
Primigravida & 97 & 48.5 \\
Multigravida (G2-G4) & 07 & 3.5 \\
Grand Multipara (> G4) & & \\
Gestational Age & 80 & 40 \\
37-38 Weeks & 96 & 48 \\
39-40 Weeks & 24 & 12 \\
>40 Weeks & & \\
\hline
\end{tabular}

the developing world, several countries have maternal mortality rates in excess of 100 women per 100,000 live births and World Health Organization statistics suggest that $25 \%$ of maternal deaths are due to $\mathrm{PPH}$, accounting for more than 100,000 maternal deaths per year. The most recent "practice bulletin" from American college of Obstetrics and Gynecologists places the estimate at 1, 40,000 maternal deaths per year or 1 woman every 4 minutes. ${ }^{8}$ According to WHO Reproductive Health library (March 2009), ${ }^{9}$ active management of third stage of labor was associated with less blood loss, lower risk of blood transfusion, reduced duration of the third stage of labor and reduced risk of maternal anemia as compared to expectant management. However, active management of third stage of labor was associated with increased risk of nausea, vomiting and raised blood pressure. Begley $\mathrm{CM}$ et al ${ }^{10}$ concluded that active management of third stage of labor had a significant decrease in mean maternal blood loss at birth, maternal blood transfusion and use of additional therapeutic uterotonics during the third stage or within the first 24 hours of labor but there was a significant increase in maternal diastolic blood pressure, vomiting after birth, after-pains and use of analgesia from birth up to discharge from the labor ward.

The present study "A comparative study of efficacy of rectal misoprostol with intravenous ergometrine and intramuscular PGF $2 \alpha$ in active management of third stage of labor" was carried out on 200 cases who were admitted to Department of Obstetrics and Gynecology, Jhalawar medical college, Jhalawar in year 2017-2018.

In our study, the mean maternal age was 24.96 years in the misoprostol group, 24.46 years in ergometrine group, 24.54 year in Carboprost group and 23.80 year in the control 
Table 2: Comparison of various drug groups in the study participants

\begin{tabular}{|c|c|c|c|c|}
\hline Drug Group & $\mathbf{n}=\mathbf{2 0 0}$ & Mean & SD & p-Value \\
\hline \multicolumn{5}{|c|}{ Mean maternal age in different drug groups } \\
\hline Misoprostol & 50 & 24.96 & 4.29 & \multirow{4}{*}{0.509} \\
\hline Ergometrine & 50 & 24.46 & 3.81 & \\
\hline Carboprost & 50 & 24.54 & 3.59 & \\
\hline Control & 50 & 23.80 & 3.68 & \\
\hline \multicolumn{5}{|c|}{ Mean Gestational Age among different drug groups } \\
\hline Misoprostol & 50 & 38.19 & 1.60 & \multirow{4}{*}{0.080} \\
\hline Ergometrine & 50 & 38.73 & 1.22 & \\
\hline Carboprost & 50 & 38.50 & 1.34 & \\
\hline Control & 50 & 38.86 & 1.31 & \\
\hline \multicolumn{5}{|c|}{ Mean duration of 3rd stage of labour in different drug groups } \\
\hline Misoprostol & 50 & 8.88 & 4.83 & \multirow{4}{*}{0.659} \\
\hline Ergometrine & 50 & 10.80 & 10.59 & \\
\hline Carboprost & 50 & 10.57 & 14.03 & \\
\hline Control & 50 & 9.24 & 2.85 & \\
\hline \multicolumn{5}{|c|}{ Mean blood loss among various drug groups (in ml) } \\
\hline Misoprostol & 50 & 139.20 & 10.92 & \multirow{4}{*}{$0.007 *$} \\
\hline Ergometrine & 50 & 152.00 & 52.83 & \\
\hline Carboprost & 50 & 168.80 & 79.37 & \\
\hline Control & 50 & 201.80 & 22.81 & \\
\hline \multicolumn{5}{|c|}{ Difference in $\mathrm{Hb}$ (pre and post-delivery) in different drug groups } \\
\hline Misoprostol & 50 & 0.59 & 0.43 & \multirow{4}{*}{$0.022 *$} \\
\hline Ergometrine & 50 & 0.71 & 0.40 & \\
\hline Carboprost & 50 & 0.76 & 0.41 & \\
\hline Control & 50 & 0.83 & 0.27 & \\
\hline
\end{tabular}

SD: Standard deviation; Hb: Hemoglobin, P-value $<0.05$ is considered significant

Table 3: Reported side effects with different drug groups during the study

\begin{tabular}{|c|c|c|c|c|c|}
\hline \multirow{2}{*}{ Side effects } & \multicolumn{4}{|c|}{ Drugs } & \multirow{2}{*}{ Value } \\
\hline & $\begin{array}{r}\text { Misoprostol } \\
\mathbf{n = 5 0}(\%)\end{array}$ & $\begin{array}{c}\text { Ergometrine } \\
\mathbf{n}=50(\%)\end{array}$ & $\begin{array}{r}\text { Carboprost } \\
\mathbf{n}=\mathbf{5 0}(\%)\end{array}$ & $\begin{array}{l}\text { Control } \\
\mathbf{n}=50(\%)\end{array}$ & \\
\hline $\begin{array}{l}\text { Total no of patients } \\
\text { with side effects }\end{array}$ & $04(8)$ & $01(2)$ & $10(20)$ & $0(0)$ & \\
\hline Diarrhea & $1(2)$ & $0(0)$ & $2(4)$ & $0(0)$ & \\
\hline Nausea & $1(2)$ & $1(2)$ & $1(2)$ & $0(0)$ & $0.049 *$ \\
\hline Pain Abdomen & $1(2)$ & $0(0)$ & $1(2)$ & $0(0)$ & \\
\hline Pyrexia & $1(2)$ & $0(0)$ & $0(0)$ & $0(0)$ & \\
\hline shivering & $0(0)$ & $0(0)$ & $3(6)$ & $0(0)$ & \\
\hline Vomiting & $0(0)$ & $0(0)$ & $3(6)$ & $0(0)$ & \\
\hline
\end{tabular}

Table 4: Complications reported during the study

\begin{tabular}{lccccc}
\hline Complications & \multicolumn{2}{c}{ Drug } & \multicolumn{2}{c}{ Total } & Value \\
& $\begin{array}{c}\text { Misoprostol } \\
\mathbf{n = 5 0}(\%)\end{array}$ & $\begin{array}{c}\text { Ergometrine } \\
\mathbf{n = 5 0}(\%)\end{array}$ & $\begin{array}{c}\text { Carboprost } \\
\mathbf{n = 5 0 ( \% )}\end{array}$ & $\begin{array}{c}\text { Control } \\
\mathbf{n = 5 0}(\%)\end{array}$ & $0.031 *$ \\
No complication & $50(100)$ & & $48(96)$ & $44(88)$ & $191(95.5)$ \\
Atonic PPH & $0(0)$ & $1(2)$ & $6(12)$ & $7(3.5)$ & $2(1.0)$ \\
Retained Placenta & $0(0)$ & $1(2)$ & $0(0)$ & \\
\hline
\end{tabular}

NB: The above complication were reported during $3^{\text {rd }}$ stage of labour 
group. The difference in age groups was not statistically significant. In a similar study by Frederic et al. ${ }^{11}$ who compared misoprostol with ergometrine; mean maternal age in misoprostol group was 23.39 years and in methyl ergometrine was 23.59 years which was not statistically significant. The results are similar to our study.

In study by Neelamma B. Patil et al ${ }^{12}$ who compared misoprostol with ergometrine; mean maternal age in misoprostol group was 23.39 years and in ergometrine group was 23.59 years which was not statistically significant. These results are similar to our study.

In present study mean gestational age is 38.19 weeks in misoprostol group, 38.73 weeks in methyl ergometrine group, 38.50 weeks in Carboprost group and 38.86 weeks in control group which in not statistically significant $(\mathrm{P}=0.080)$. Neelamma B. Patil et al. ${ }^{12}$ who compared $600 \mathrm{mcg}$ misoprostol with $0.2 \mathrm{mg}$ methyl ergometrine for prevention of postpartum hemorrhage in 200 women having vaginal delivery, mean gestational age was 38.72 weeks in misoprostol group and 39.19 weeks in ergometrine group which is similar to our study although results are not statistically significant.

In the present study the mean duration of third stage of labor was $10.80 \mathrm{~min}, 10.57 \mathrm{~min}, 8.88$ and 9.24 minutes in ergometrine, Carboprost, misoprostol and control group respectively. There was no statistically significant difference between the duration of third stage of labor in all the groups as determined by the chi square test $(\mathrm{p}=0.659)$. In study by Vrunda Joshi et al ${ }^{8}$ when misoprostol was compared to methyl ergometrine, there was reduction in mean duration of third stage of labor from $4.18 \mathrm{~min}$ in ergometrine group to 3.98 min misoprostol group which was not significant statistically $(\mathrm{P}=0.823)$.

In another study by Bugalho and Daniel $\mathrm{A}$ et $\mathrm{al}^{13}$ where $400 \mathrm{mcg}$ rectal misoprostol was compared with 10 units of oxytocin in 663 women in a double blinded randomized clinical trial, no significant difference was observed between the duration of third stage of labor between the two groups. In a study by Diab KM et al ${ }^{14}$ who compared rectal misoprostol with combined intramuscular oxytocin and ergometrine, also had similar results. In a study by J Harriott et $\mathrm{al}^{15}$ who compared syntometrine with misoprostol in AMTSL, mean duration of $3^{\text {rd }}$ stage of labor was $8.4 \pm 1.4$ min in syntometrine group and $7.8 \pm 1.2 \mathrm{~min}$ in misoprostol group which was not statistically significant. The study had similar results when compared to our study.

In the present study, the mean blood loss was 139.20 $\mathrm{ml}$ in Misoprostol group as compared to $152.00 \mathrm{ml}$, $168.80 \mathrm{ml}$ and $201.80 \mathrm{ml}$ in ergometrine, Carboprost and Control groups respectively. There was a statistically significant difference between the average blood loss in all groups $(\mathrm{p}=0.007)$. Reduction in blood loss was statistically significant in misoprostol group as compared to ergometrine, Carboprost and control groups. The results of our study are comparable to the study conducted by $\mathrm{N}$ Prata et $\mathrm{al}^{16}$ who compared the 'current practices group' for active management of third stage of labor with that of "misoprostol group"(10 unit syntocinon intramuscular used in active management of third stage of labor vs $600 \mathrm{mcg}$ of oral misoprostol). Women in the misoprostol group were less likely to bleed $500 \mathrm{ml}$ or more. He concluded that misoprostol should be considered for inclusion in the AMTSL protocol as the mean blood loss was less in misoprostol group.

In the study by Vrunda Joshi et al, ${ }^{8}$ ergometrine was compared with misoprostol. There was $200.87 \mathrm{ml}$ mean blood loss in ergometrine group while lesser amount of blood loss i.e. $195 \mathrm{ml}$ blood loss was seen in misoprostol group. Reduction in blood loss was statistically significant in misoprostol group as compared to ergometrine. These results were comparable with our study.

J. Harriottet al ${ }^{15}$ compared syntometrine with rectal Misoprostol. Mean blood loss in misoprostol group was $180.1 \pm 120 \mathrm{ml}$ and in syntometrine group was $197 \pm 176.97 \mathrm{ml}$ which was comparable to our study. B Jaju Puroshottamet al ${ }^{17}$ compared intramuscular PGF2 $\alpha$ with intravenous ergometrine during active management of third stage of labor. He found that prophylactic PGF $2 \alpha$ is a better alternative as compared to intravenous ergometrine. The mean blood loss $(\mathrm{p}<0.001)$ and the duration of third stage of labor $(\mathrm{P}<0.001)$ was significantly lower in the Carboprost group. The results are discordant when compared to our study.

In recent study of 1620 women by Derman RJ et al, ${ }^{18}$ giving birth in a rural setting in India, misoprostol given after delivery was found to be more effective than placebo in reducing the rate of postpartum hemorrhage and mean postpartum blood loss but side effects of shivering and fever were more frequent with misoprostol then with placebo.

In our study the mean difference in hemoglobin was 0.59 $\pm 0.43 \mathrm{gm} / \mathrm{dl}$ in misoprostol group, $0.71 \pm 0.40 \mathrm{gm} / \mathrm{dl}$ in methyl ergometrine group, $0.76 \pm 0.41 \mathrm{gm} / \mathrm{dl}$ in Carboprost group and $0.83 \pm 0.27 \mathrm{gm} / \mathrm{dl}$ in control group. Difference was significant among groups which was determined by applying the chi square test $(\mathrm{p}<0.0001)$. However the decrease in hemoglobin was the least in the misoprostol group and highest in the control group. In a study conducted by Diab KM et al ${ }^{14}$ in which he compared the effectiveness of rectal misoprostol with that of combined oxytocin and ergometrine drugs. The difference in hemoglobin before and after delivery was more in combined oxytocin-ergometrine group as compared to misoprostol group. These results are comparable to our study.

In a study conducted by Vimla $\mathrm{N}$ Mittalet al ${ }^{19}$ who compared sublingual misoprostol with intraveneous ergometrine; difference in $\mathrm{HB}$ was $0.8 \mathrm{gm} / \mathrm{dl}$ in ergometrine and $0.7 \mathrm{gm} / \mathrm{dl}$ in misoprostol group. These results are similar to our study. 
In our study when side effects associated with different drug groups were compared, A total of $15(7.5 \%)$ participants reported with side effects, maximum 10 $(5 \%)$ in the Carboprost group. The reported side effects included diarrhea, nausea, shivering and vomiting in $(1.5 \%)$ participants. The association of the drug group and the reported side effects was statistically significant $(\mathrm{p}=0.049)$. Side effects were however self-limited and subsided within 10-15 minutes in all cases.

These finding were comparable with the 'WHO multicentric trial ${ }^{20}$ in which misoprostol and oxytocin were compared for side effects. They concluded that oral misoprostol was associated with significantly higher incidence of side effects like shivering and rise in body temperature when compared with oxytocin. Hence oxytocin is preferred to $600 \mathrm{mcg}$ of misoprostol in active management of third stage of labor in hospital settings, but still misoprostol has been suggested for the management of third stage of labor in developing countries because it has strong uterotonic effects, can be given easily given (orally, rectally, sublingually), inexpensive and does not need refrigeration.

Frederic et al $^{11}$ in their double blind study compared ergometrine with misoprostol. They concluded that although protection from postpartum hemorrhage using parenteral ergometrine and misoprostol is nearly equal: Misoprostol is associated with more side effects. But side effects of Misoprostol were self-limiting. The results of this study are similar to our study. Another study by Gallos ID et al. ${ }^{21}$ reported that ergometrine plus oxytocin combination, carbetocin, and misoprostol plus oxytocin combination may have some additional desirable effects compared with the current standard oxytocin. The two combination regimens, however, are associated with significant side effects. Moreover, these were more effective for blood loss of more than $500 \mathrm{ml}$, such was not the case in our study.

In our study, 2 patients; one patient from the ergometrine group and other from Carboprost group had retained placenta. Postpartum hemorrhage was seen in 7 women; 6 patients were from control group and 1 patient was from Carboprost group. None of the patients from misoprostol had retained placenta or PPH. There is a statistically significant variation found among groups according to complications $(\mathrm{P}=0.031)$. Vrunda Joshiet $\mathrm{al}^{8}$ also found a higher incidence of retained placenta associated with the use of methyl ergometrine when compared with rectal misoprostol. This study is comparable to our study as none of the patients in my study from misoprostol group had retained placenta when compared with ergometrine group (2\% patients had retained placenta).

In a study by Neelamma B. Patil et al $^{12}$ incidence of postpartum hemorrhage was less $(6 \%)$ in misoprostol group as compared to Ergometrine (9\%). This study is comparable to our study. In our study there is no incidence of PPH in misoprostol group as compared to other groups (Ergometrine, Carboprost and control groups).

Amant et al $^{11}$ compared the efficacy of $600 \mathrm{mcg}$ oral misoprostol and $0.2 \mathrm{mg}$ of intravenous ergometrine in 200 women with apparently normal pregnancies for prevention of postpartum hemorrhage. Postpartum hemorrhage occurred in $4.3 \%$ of ergometrine group and $8.3 \%$ of misoprostol group $(\mathrm{p}=0.57)$ which was not significant. This study contradicts with the results of our study as higher incidence of PPH was seen in control group as no uterotonic was given.

EI Refaey et $a^{22}$ investigated the use of oral $\mathrm{PGE}_{1}$ analogues, misoprostol in the prevention of postpartum hemorrhage in 237 consecutive women undergoing vaginal delivery. Postpartum hemorrhage occurred in $6 \%$ of the women and the median length of third stage was 5 minute. It was concluded that misoprostol may be effective in the prevention of postpartum hemorrhage. This study is comparable to our study.

Prostaglandins have proven value in management of $\mathrm{PPH}$ even in cases not responding to syntometrine/oxytocin. A Cochrane review by Tunçalp Ö, et al. ${ }^{23}$ has also reported that the prostaglandins are still the best uterotonics in practice. Furthermore, numerous studies advocating the off label use of misoprostol have shown varying efficacy based on route of administration and dose. Misoprostol was found less effective than injectable uterotonics but good results when compared to placebo in reducing blood loss. ${ }^{22}$ Pharmacokinetics suggests that the median onset of action of oral misoprostol (6 min, range 4-10 min) results in earlier clinical efficacy but in practice rectal misoprostol offers a longer duration of sustained uterine contractility even though its onset of action in slower. ${ }^{15}$

Other distinct advantage of rectal route of administration of misoprostol includes its post-partum administration in patients with vomiting (which is not an uncommon intra partum event) and in those patients unable to take medication due to anesthesia. Rectal misoprostol is associated with less systemic side effects and good option for domiciliary setting where parenteral access is not an option. But care should be taken in training the health care provider regarding the proper use of misoprostol, so that possible harmful effects like its use before delivery which can lead to uterine rupture and overdosing are avoided. ${ }^{24}$

\section{Conclusion}

Misoprostol can be used as a safe and effective alternative agent in active management of third stage of labor. As in developing countries with a high prevalence of anemia, even a small reduction in blood loss would be clinically significant. Per rectal misoprostol is an equal or better alternative when compared with ergometrine or PGF $2 \alpha$ and can prove to be better alternative. 


\section{Source of Funding}

None Declared.

\section{Conflict of Interest}

None Declared.

\section{Acknowledgement}

Author acknowledges the role of study participants and timely completion of this study.

\section{Authors Contribution}

Iqbal S.(A), Malik MA.(B), Aggarwal M.(C), Bairwa R.(D)

" $A$ " designed the research, collected and analyzed data and co-wrote the paper, "B" analyzed the data, co-wrote the paper, " $C$ " designed the research, supervised the research and edited the final version of the paper, "D" supervised the research, provided valuable inputs, interpreted the data and edited the initial version of the paper.

\section{References}

1. Bajwa SK, Bajwa SJS, Goraya SPS, Kaur H, KaurIshar H, Singh A. Management of third stage of labor with misoprostol: A comparison of three routes of administration. Perspect Clin Res. 2012;3(3):102. doi: $10.4103 / 2229-3485.100666$.

2. Maughan KL, Heim SW, Galazka SS. Preventing postpartum hemorrhage: managing the third stage of labor. AAFP. 2006;73(6):1025-8.

3. Berg CJ, Atrash HK, Koonin LM, Tucker M. Pregnancy-related mortality in the United States. Obstet Gynecol. 1987;88:161-7.

4. Hofmeyr GJ, Ferreira S, Nikodem VC, Mangesi L, Singata M, Jafta Z, et al. Misoprostol for treating postpartum haemorrhage: a randomized controlled trial [ISRCTN72263357]. BMC Pregnancy Childbirth.

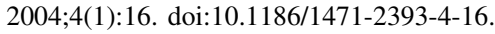

5. Kumari R, Mendiratta SL, Kumari P, Renu. Comparison of efficacy and safety of I/M PGF $2 \alpha$ versus I/V Methyl Ergometrine in the Active Management of third Stage of Labor. Indian Obstet Gynaecol. 2015;5(1):19-22.

6. Saleem MS. Modified Kuppuswamy Scale Updated for Year 2018. Paripex- Indian J Res. 2018;7(3):436.

7. Anderson JM, Itches D. Prevention and management of Post partum hemorrhage. Am Fam Physician. 2007;75(6):875-82.

8. Smith JR. Postpartum hemorrhage, medscape august 2011.

9. Abalos E. Active versus expectant management of the third stage of labor: RHL commentary (lat revised: 2 March 2009). The WHO Reproductive Health Library; Genaeva: World Health Organization.

10. Begley CM, Gyte GML, Devane D, McGuire W, Weeks A. Active versus expectant management for women in the third stage of labour. Cochrane Database Syst Rev. 2011;9(11):CD007412. do1:10.1002/14651858.CD007412.pub3.

11. Amant F, Spitz B, Timmerman D, Corremans A, Assche FAV. Annick Corremans and France Andre Vas Assche, Misoprostol compared with methyl ergometrine for prevention of PPH a double blind randomized trial. Br J Obstet Gynecol. 1999;106(10):1066-70. doi:10.111/1.1471-0528.1999.tb08115.x.

12. Patil NB. A randomized controlled trial of oral Misoprostol vs injection methylergometrine for prevention of post partum hemorrhage. Int J Reprod Contracept Obstet Gynecol. 2013;2(3):296303.

13. Bugalho A, Daniel A, Faúndes A, Cunha M. Misoprostol for prevention of postpartum hemorrhage. Int $J$ Gynecol Obstet. 2001;73(1):1-6. [01:10.1016/50020-7292(01)00346-0.

14. Diab KM, Ramy AR, Yehia MA. The Use of Rectal Misoprostol as Active Pharmacological Management of the Third Stage of Labor. J Obstet Gynaecol Res. 1999;25(5):327-32. do1:10.1111/].1447-

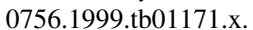

15. Harrtiott J, Christie L, Wynter S, DaCosta V, Fletcher H, Reid M. A randomized comparison of rectal misoprostol with syntometrine on blood loss in the third stage of labour. West Indian Med J. 2009;58(3):201-6.

16. Prata N, Hamza S, Gypson R, Nada K, Vahidnia F, Potts M. Misoprostol and active management of the third stage of labor. Int $J$ Gynecol Obstet. 2006;94(2):149-55. [01:10.1016/1.1]go.2006.05.027.

17. Purushottam BJ, Roopa P. Prophylactic intramuscular versus intravenous methyl erogmetrine for prevention of atonic PPH in high risk women. J Obsetet Gynaecol India. 2008;p. 58417-420.

18. Derman RJ, Kodkany BS, Goudar SS, Geller SE, Naik VA, Bellad $\mathrm{MB}$, et al. Oral misoprostol in preventing postpartum haemorrhage in resource-poor communities: a randomised controlled trial. Lancet. 2006;368(9543):1248-53. do1:10.1016/s0140-6/36(06)69522-6.

19. Vimala N, Mittal S, Kumar S, Dadhwal V, Mehta S. Sublingual misoprostol versus methylergometrine for active management of the third stage of labor. Int J Gynecol Obstet. 2004;87(1):1-5. doi:10.1016/].11g0.2004.05.016.

20. Gülmezoglu AM, Villar J, Ngoc NT, Piaggio G, Carroli G, Adetoro $\mathrm{L}$, et al. WHO multicentre randomised trial of misoprostol in the management of the third stage of labour. Lancet. 2001;358(9283):689-95. Hoi:10.1016/s0140-6736(01)05835-4.

21. Gallos ID, Williams HM, Price MJ, Merriel A, Gee H, Lissauer D, et al. Uterotonic agents for preventing postpartum haemorrhage: a network meta-analysis. Cochrane Database Syst Rev. 2018;4(4):CD011689. do1:10.1002/14651858.CD011689.pub4

22. El-Refaey H, O'Brien P, Morafa W, Walder J, Rodeck C. Use of oral misoprostol in the prevention of postpartum hemorrhage. Br J Obstet Gynaecol. 1997;104(3):336-9.

23. Tunçalp Ö, Hofmeyr GJ, Gülmezoglu AM. Prostaglandins for preventing postpartum haemorrhage. Cochrane Database Syst Rev. 2012;2012(8). doi:10.1002/14651858.cd000494.pub4

24. Walraven G, Blum J, Dampha Y, Sowe M, Morison L, Winikoff B, et al. Misoprostol in the management of the third stage of labour in the home delivery setting in rural Gambia: a randomised controlled trial. Br J Obstet Gynecon. 2005;112(9):1277-83. do1:10.1111/].147T$052820050071 \mathrm{x}$

\section{Author biography}

Suhail Iqbal, Senior Resident

Mehak Ayoob Malik, Junior Resident

Manju Aggarwal, Professor

Radheshyam Bairwa, Associate Professor

Cite this article: Iqbal S, Malik MA, Aggarwal M, Bairwa R. A comparative study of efficacy of rectal misoprostol with intravenous methyl ergometrine and intramuscular PGF2 $\alpha$ in active management of third stage of labor. Indian J Obstet Gynecol Res 2020;7(4):533-539. 